\title{
An Unusual Case Report of Erythematous Lichen Planus in a 23 Year Old Female
}

\author{
KIRANDEEP KAUR', MRIDHA SHARMA², GURKIRAN KAUR³
}

Oral Lichen planus (OLP) or lichen ruber planus is was first described by Wilson in 1869 and affects about $0.5^{-1} \%$ of the population and $2.6 \%$ of the Indian population. It is more frequently present in the female population with age usually above 50 years which is inconsistent with the present case. The rate of malignant transformation of OLP is quite low, although erythematous OLP has a higher incidence. The diagnosis of OLP is done on the basis of clinical examination (oral and skin lesions), biopsy and direct immunofluorescence and its management is aimed mainly at palliation of the symptoms. The basic treatment for OLP includes topical and systemic corticosteroids

KEYWORDS: Lichen Planus, Erythematous, Burning Sensation

\section{INTRODUCTION}

Lichen planus or lichen ruber planus was first described by Wilson in 1869 . It is primarily a dermatological disease involving the skin. It affects about $0.5-1 \%$ of the population and $2.6 \%$ of the Indian population. ${ }^{1}$ Oral lichen Planus (OLP) is an inflammatory disease involving the oral mucosa. The exact etiology is unknown. However, the cofactors in causing the disease include mental stress, Diabetes mellitus, drugs, Hepatitis $C$ virus association. The pathogenesis of lichen planus involves a cell mediated degeneration of basal cell layer of epithelium. ${ }^{2}$ The classic appearance of skin lesions consists of erythematous to violaceous papules that are flat topped and occasionally polygonal in form. A network of fine lines (Wickham's striae) is often present. The oral lesions are classified into reticular (most common), erythematous (atrophic), plaque, bullous (least common), papular and ulcerative varieties. ${ }^{3}$ The buccal mucosa is most commonly involved. The striae are typically bilateral in a symmetrical form on the buccal mucosa. The diagnosis of OLP is done on the basis of clinical examination (oral and skin lesions), biopsy and direct immunofluorescence. Malignant transformation of the atrophic variety is the highest (0.4-5.6\%) whereas the reticular variety is very unlikely to undergo malignant transformation. ${ }^{4}$ The primary treatment aims at the alleviation of symptoms such as burning sensation on eating spicy foods. It also depends on the severity of the disease. Topical and systemic steroids such as Triamcinolone acetonide, clobetasol propionate ointments and prednisone respectively are the mainstay of treatment. Other immunosuppressive agents such as azathioprine and cyclosporine can be given. ${ }^{5}$

\section{CASE REPORT}

A 23 year old female patient came to the dental clinic with a chief complaint of burning sensation on the left and right inner cheek since the past 6 months. The history dated back to 6 months when the patient experienced burning sensation on eating spicy and hot foods w.r.t the right back inner cheek region. The burning sensation was intermittent and started only on eating spicy foods and ended on removal of stimulus. A history of mental stress was present. On intra-oral examination, hard tissue examination was non-contributory. On soft tissue examination, a mixed red and white lesion with irregular borders was present on the right buccal mucosa adjacent to 46 and 47 . It was about $4 \mathrm{cms}$ posterior from the commissure and about $1 \mathrm{~cm}$ inferior to the line of occlusion (Figure 1). A similar lesion was present on the buccal mucosa adjacent to 16 and 17 that extended into gingiva. Erythema was also seen w.r.t buccal attached gingiva of 17 There were no secondary changes such as ulceration, bleeding or purulent discharge (Figure 2). Surrounding mucosa appeared normal. On palpation, the inspectory findings of the lesion were confirmed. The lesion was tender, non-scrapable and it did not disappear on stretching. There was no loss of pliability of mucosa. No bands were present. Surface of the lesion appeared smooth and no secondary changes were elicited. 
Similarly, a white lesion with diffuse margins was present on the left buccal mucosa adjacent to 36 and 37. The lesion appeared as elevated striae extending from the centre towards the periphery interspersed with the normal mucosa. Erythematous areas were present within the lesion. Surrounding mucosa was normal in appearance. On palpation, the lesion was similar to that of right buccal mucosa.

A provisional diagnosis based on the clinical findings was Reticular and Erythematous lichen planus of right buccal mucosa and maxillary buccal attached gingiva w.r.t 17 and same for left buccal mucosa. The differential diagnosis included lichenoid reaction, DLE, desquamative gingivitis and frictional keratosis. The treatment included topical triamcinolone in orabase ointment to be used thrice a day for 1 week and tetracycline mouthrinse, 250mg capsules to be opened, dissolved in water and rinsed thrice a day for 1 week. Additionally patient was given antioxidants. The patient was put on periodic recall once every 3 months.

\section{DISCUSSION}

OLP is a chronic immune mediated disease which affects the skin, oral mucosa, scalp, nails and genital mucosa. ${ }^{6}$ It is more frequently present in the female population with age usually above 50 years which is inconsistent with the present case. The exact etiology of OLP is unknown. However, the role of mental stress, drugs, dental materials, Hepatitis $C$ virus has been postulated. ${ }^{2,3}$ An atypical cytotoxic T cell mediated immune response has been reported in the pathogenesis of OLP. ${ }^{2}$ In contrast to the reticular and plaque type variants of OLP, the erythematous variety of OLP is symptomatic and requires immediate treatment.3,4 When the erythematous component extends to the gingiva, it is known as Desquamative gingivitis. OLP should be differentiated from lesions such as DLE, lichenoid reaction.

DLE lesions show striae ending sharply. ${ }^{7}$ However, the pathognomonic 'butterfly rash' was not present in the present case. Further, the absence of drug intake for any medical condition and restored teeth adjacent to the lesions ruled out drug induced and contact lichenoid reactions respectively. ${ }^{3,8,9}$ The rate of malignant transformation of OLP is quite low, although erythematous OLP has a higher incidence. ${ }^{9}$ Diagnosis should be prompt and correct to rule out dysplasia. The management is aimed mainly at palliation of the symptoms. The basic treatment includes topical and systemic corticosteroids. Adjuvants such as immunomodulator drugs (Cyclosporine, Azathioprine) can be given for refractory cases along with retinoids, Psoralen UV-A therapy, $\mathrm{CO}_{2}$ laser can also be used., 3

\section{REFERENCES}

1. Vincent SD, Fotos PG, Baker KA, Williams TP. Oral lichen planus: the clinical, historical and therapeutic features of 100 cases. Oral Surg Oral Med Oral Pathol. 1990; 70(2):165-71.

2.Lavanya N, Jayanthi P, Rao UK, Ranganathan K. Oral lichen planus: An update on pathogenesis and treatment. J Oral Maxillofac Pathol. 2011;15(2):127-32. 3. Burket LW, Greenberg MS, Glick M. Burket's Oral Medicine: Diagnosis \& Treatment. 12th ed.

4. Silverman S Jr, Gorsky M, Lozada-Nur F. A prospective follow-up study of 570 patients with oral lichen planus: persistence, remission, and malignant association. Oral Surg Oral Med Oral Pathol. 1985;60(1):30-4.

5. Edwards PC, Kelsch R. Oral lichen planus: Clinical presentation and management. J Can Dent Assoc 2002;68:494-9.

6. Sugerman PB, Savage NW. Oral lichen planus: Causes, diagnosis and management. Aust Dent J 2002; 47:290-7.

7. Schiødt M. Oral manifestations of lupus erythematosus. Int J Oral Surg 1984;13:101-47.

8. Fitzpatrick SG, Hirsch SA, Gordon SC. The malignant transformation of oral lichen planus and oral lichenoid lesions: A systematic review. J Am Dent Assoc 2014; 145:45-56.

9. Ismail SB, Kumar SK, Zain RB. Oral lichen planus and lichenoid reactions: Etiopathogenesis, diagnosis, management and malignant transformation. J Oral Sci 2007;49:89-106. 
Source of support: Nil, Conflict of interest: None declared

\section{AUTHOR AFFILIATIONS:}

1. BDS, 96 Brighton, 11-street, Brooklyn, 11235, New-York, USA

2. BDS, 58-Shingar Avenue, Chheharta, Amritsar, India

3. BDS, 14064, Lotus Lane \#421, Centerville, VA 20120 USA

\section{Cite this article as:}

Kaur K, Sharma M, Kaur G. An Unusual Case Report of Erythematous Lichen Planus in a 23 Year Old Female. Int Healthcare Res J 2018;2(2):38-40. doi: 10.26440/IHRJ/o2_02/166

\section{Corresponding Author:}

Dr. Mridha Sharma

58-Shingar Avenue

Chheharta, Amritsar, India
For article enquiry/author contact details, e-mail at: manuscriptenquiry.ihrj@gmail.com

\section{LEGENDS}

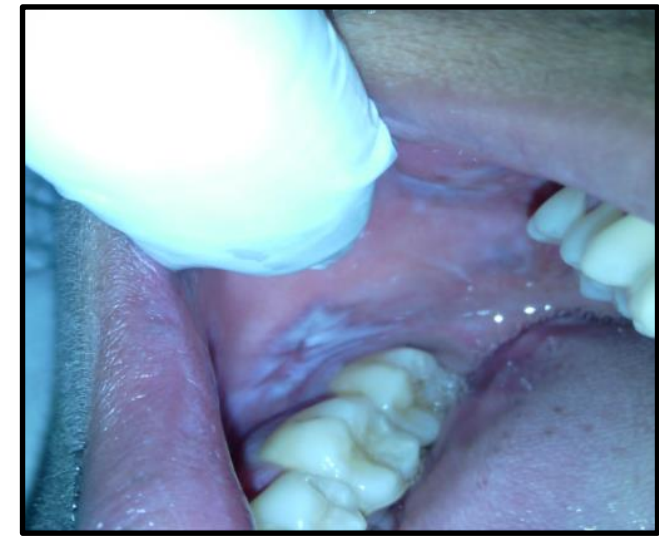

Figure 1. Mixed red and white lesion with irregular borders was present on the right buccal mucosa adjacent to 46 and 47

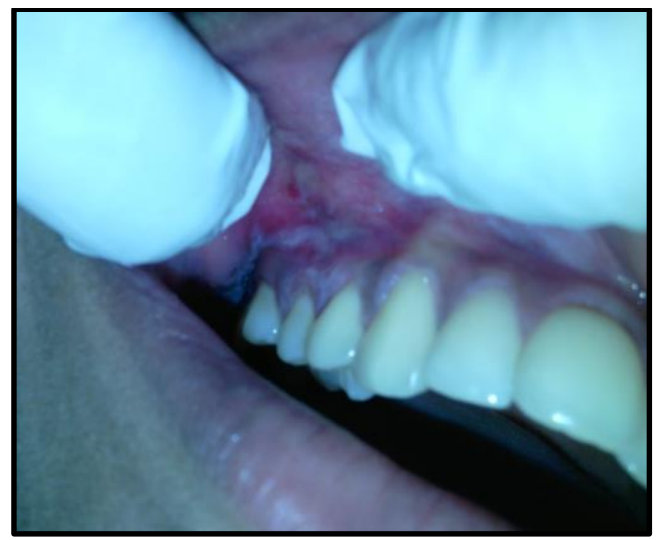

Figure 2. Mixed red and white lesion with erythema present on the buccal mucosa adjacent to 16 and 17 that extended into gingiva. 